\title{
COBERTURA JORNALÍSTICA DO PERIGO CLIMÁTICO (SECA) 2012-2015 NA BAHIA: ENTRE O COMBATE E A CONVIVÊNCIA COM A SECA
}

\author{
Rafael Vinicius de São José \\ Universidade Estadual de Campinas, Instituto de Geociências, Campinas, SP, Brasil \\ Centro de Pesquisas Meteorológicas e Climáticas Aplicadas à Agricultura, Campinas, SP, Brasil \\ saojoserafaelvinicius16@gmail.com
}

Priscila Pereira Coltri Centro de Pesquisas Meteorológicas e Climáticas Aplicadas à Agricultura, UNICAMP, Campinas, SP, Brasil Universidade Estadual de Campinas, Instituto de Geociências, Campinas, SP, Brasil pcoltri@unicamp.br

Roberto Greco Universidade Estadual de Campinas, Instituto de Geociências, Campinas, SP, Brasil robertogreco01@yahoo.it

Kezia Andrade dos Santos keziapeniel@gmail.com

Ivonice Sena de Souza

Secretaria de Educação do Estado da Bahia vonisouza@yahoo.com.br

Guilherme Almussa Leite Torres Universidade Estadual de Campinas, Instituto de Geociências, Campinas, SP, Brasil guialmussa@gmail.com

Ralph Charles Universidade Estadual de Campinas, Instituto de Geociências, Campinas, SP, Brasil r123747@dac.unicamp.br

\begin{abstract}
RESUMO
Entre os anos de 2012 a 2015, o Brasil enfrentou uma condição de seca plurianual, atingindo diversos setores da sociedade civil. A redução da disponibilidade de água, especialmente no semiárido baiano, colocou em evidência as políticas hídricas públicas realizadas na Bahia, estado localizado na região Nordeste do Brasil. Nesse mesmo quadriênio crítico, em termos de baixas precipitações, os jornais locais realizaram a cobertura desse importante evento climático. O presente trabalho é baseado nas matérias publicadas por dois jornais de grande circulação no estado da Bahia. O objetivo foi analisar as notícias que abordavam os conceitos "combate à seca" e "convivência" com este evento e com o semiárido, publicadas pela mídia local. Para tanto, selecionou-se matérias veiculadas entre os anos de 2012 a 2015. Concluiu-se que a mídia permanece com a visão reducionista e fragmentada sobre o semiárido e o fenômeno da seca, não aderindo a uma importante abordagem desenvolvida a partir dos anos de 1990 por organizações sociais de convivência com a seca, que aborda princípios da sustentabilidade ambiental, econômica, social e cultural.
\end{abstract}

Palavras-chave: Gestão hídrica. Sertão. Semiaridez. Comunicação.

\section{JOURNALISTIC COVERAGE OF THE 2012-2015 DROUGHT PHENOMENON IN BAHIA: BETWEEN COMBAT AND LIVING WITH THE DROUGHT}

\begin{abstract}
Between 2012 and 2015, Brazil faced a multi-annual drought condition, affecting various sectors of civil society. The reduction in water availability, especially in the semiarid region of Bahia, highlighted the public water policies carried out in Bahia, a state located in the northeast of Brazil. In that same critical quadrennium, in terms of low rainfall, local newspapers covered this important climatic event. The present work is based on the articles published by two opinion newspapers of great regional circulation in the state of Bahia. The objective was to analyze the news that addressed the concepts of combating drought and living with this event and with the region, published by the local media. To this end, we
\end{abstract}

$\begin{array}{lllll}\text { Caminhos de Geografia } & \text { Uberlândia } & \text { v. 22, n. } 84 & \text { dez/2021 } & \text { p. 136-153 Página } 136\end{array}$


selected articles published between 2012 and 2015. It was concluded that the media remains with a reductionist and fragmented view on the semiarid and the drought phenomenon-combating combating drought), not adhering to an important approach developed from the 1990 onwards, by social organizations living with the drought, which addresses principles of environmental, economic, social and cultural sustainability.

Keywords: Water management. Hinterland. Semiaridity Communication.

\section{INTRODUÇÃO}

As terras secas, submetidas à influência dos climas áridos, semiáridos e subúmidos secos, segundo a Convenção das Nações Unidas para o Combate à Desertificação (UNCCD), cobrem aproximadamente $41 \%$ da superfície terrestre (UNITED NATIONS, 2011) e, destas, aproximadamente $15 \%$ correspondem à região semiárida (SAFIEL e ADEEL 2005). No território brasileiro, o clima semiárido ocorre essencialmente na região Nordeste, onde a vegetação é a estepe semiárida ou a caatinga, com temperaturas elevadas e pluviosidade baixa (TORRES e MACHADO, 2016).

No Brasil, a delimitação dessa região é altamente complexa, polêmica e já perpassou por várias modificações. Na delimitação mais recente, definida pela Superintendência do Desenvolvimento do Nordeste (SUDENE) ${ }^{1}$, o semiárido brasileiro é composto por 1.262 municípios, conforme os seguintes critérios: precipitação pluviométrica média anual igual ou inferior a $800 \mathrm{~mm}$, índice de aridez de Thornthwaite igual ou inferior a 0,50 e percentual diário de déficit hídrico igual ou superior a $60 \%$, levando em consideração todos os dias do ano (SUDENE, 2018). Comparado com outras regiões semiáridas no mundo, a quantidade de precipitação pluviométrica do semiárido brasileiro faz desse semiárido o mais chuvoso do planeta.

Devido a suas particularidades ambientais, em especial as características climáticas, o Semiárido Brasileiro (SAB) está suscetível à ocorrência de secas periódicas. A seca é um dos fenômenos naturais mais complexos que afeta, recorrentemente, diversos setores da sociedade civil, principalmente em regiões com alta vulnerabilidade socioeconômica, como é o caso do Nordeste do Brasil (MALVEZZI, 2007; MARENGO, CUNHA e ALVES, 2016; SÃO JOSÉ et al, 2020a).

Historicamente, as políticas governamentais do $S A B$ foram orientadas, quase exclusivamente, para combater a seca, por meio de medidas paliativas, emergenciais (SILVA, 2007). Nessa perspectiva, instituições públicas foram criadas ao longo da história para a realização de obras contra a seca, como o Departamento Nacional de Obras Contra as Secas (DNOCS) ${ }^{2}$, que elaboraram obras com o objetivo de solucionar a escassez hídrica (SILVA, 2003; MALVEZZI, 2007 e BURITI e BARBOSA, 2018).

As políticas governamentais do SAB são guiadas pela exploração econômica, pelo controle dos recursos hídricos, por uma visão fragmentada da superação da seca e pela implementação de ações de controle a fim de beneficiar a política econômica dominante da região (PEREZ-MARIN et al., 2017). Essa dinâmica local, segundo Silva (2003), apresenta um discurso que atribui apenas à natureza a causa da miséria e do atraso regional, ocultando as problemáticas estruturais.

Esse modelo de desenvolvimento adotado pelo poder público no século XX, que ignorou os princípios da sustentabilidade ambiental, econômica, social e cultural, apresentou índices insatisfatórios de desenvolvimento regional e a situação estrutural calamitosa culminou no aumento da pobreza, particularmente nos períodos de seca (PEREZ-MARIN et al., 2017). Como uma reação a essas abordagens do governo, o modelo de desenvolvimento vigente na época foi questionado por organizações e associações que demandavam soluções permanentes para as raízes dos problemas do SAB (SILVA, 2007; DUQUE, 2008), a partir do entendimento de que a seca é um fenômeno natural e recorrente na região, incontrolável pelo homem (SÃO JOSÉ, 2019; PEREZ-MARIN et al., 2017). Assim, na perspectiva de contribuir tecnicamente para viabilizar melhores condições de vida

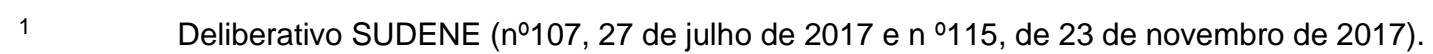

$2 \quad$ Fundado em 1909, período que foi batizado como Inspetoria de Obras Contra as Secas (IOCS).

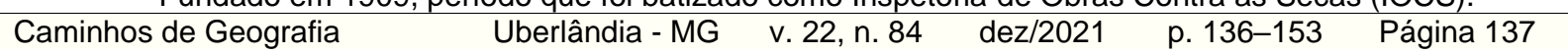


no semiárido, instituições governamentais e não governamentais vêm intensificando programas de convivência com a seca e a realidade do semiárido.

Desse modo, o presente estudo teve por objetivo analisar as notícias referentes à seca, que abordam os conceitos "combate" e "convivência" com a seca, disseminadas no fragmento temporal de 20122015. A hipótese levantada neste trabalho é que a mídia retrata, em suas matérias, as políticas governamentais de combate à seca, apresentando a visão de que esse fenômeno deve ser combatido para melhoria das condições de vida local. As notícias, nesse caso, enfatizam ações emergenciais e não a convivência e adaptação com o clima semiárido. Adicionalmente, levanta-se a hipótese de que as matérias não contribuem para o entendimento da seca enquanto um fenômeno da natureza e, portanto, constituinte do ritmo climático.

A seguir, apresenta-se uma breve abordagem de concepções teóricas e históricas, constituindo-se em um referencial para análise do assunto em questão. Nessa perspectiva, discute-se como os temas da climatologia, em especial o fenômeno da seca, são retratados pela mídia, bem como os aspectos positivos e negativos da cobertura destes temas pelos diferentes tipos de mídia; aborda-se o histórico dos paradigmas de desenvolvimento (combate à seca e a convivência com a seca e o semiárido), contextualização de singular relevância já que o foco deste trabalho é a investigação de como estes paradigmas são trabalhados nos jornais analisados e, por fim, realiza-se uma concisa discussão sobre o confronto entre o modelo de combate à seca e o de convivência para evidenciar que estes trabalham em diferentes dimensões, visto que o primeiro defende a correção do regime pluviométrico da região e caracteriza o clima como hostil. O segundo, por sua vez, apresenta uma narrativa que contradiz o primeiro.

\section{Abordagem de temas da climatologia pela mídia: o caso do fenômeno da Seca}

A divulgação do tema seca pela mídia é importante para a formação da opinião e do entendimento do público acerca de questões ambientais (O'DONNEL e RICE, 2008). Para muitos cidadãos, o acesso ao conhecimento científico se dá, largamente, por meio da mídia de massa e não por publicações científicas (NOBRE 2011). Nesse sentido, Nobre (2011) ressalta que, uma forma de proporcionar a divulgação de informações relacionadas às ciências ambientais é a partir dos veículos de comunicação de massa, com aplicação, de preferência, do jornalismo ambiental.

Embora a mídia seja, geralmente, considerada como uma influência positiva na conscientização pública (THAKER, ZHAO e LEISEROWITZ, 2017), estudos encontraram uma associação complexa entre os meios de comunicação de massa e a compreensão da ciência, principalmente no campo das ciências climáticas (ANTILLA, 2005; STEINKE et al, 2006; NUNES, 2007; NUNES, 2016; HENNESSY, HAWKINS e JAMIESON, 2017) e em países em desenvolvimento (THAKER, ZHAO e LEISEROWITZ, 2017). Na prática, há muitas influências que afetam negativamente as representações da mídia sobre assuntos climáticos, tais como conhecimento de repórteres, mal entendimento do público, limitado conhecimento científico, restrições de tempo e espaço e pressões comerciais sobre mídia para serem mais lucrativas, venda de "desastres" (O'DONNEL e RICE, 2008).

Na maioria das vezes, as pessoas têm acesso às informações referentes à Climatologia por meio dos diversos tipos de mídia, o que a torna de extrema importância para levar informação à população, em geral. Recentemente, a comunidade científica na área da Climatologia tem buscado cada vez mais estudar a divulgação de temas relacionados a essa ciência pelos diversos veículos de comunicação. Embora o potencial da mídia seja admitido nestas pesquisas (como, por exemplo, ANTILLA, 2005; STEINKE et al, 2006; NUNES, 2007; NUNES, 2016; SÃO JOSÉ et al., 2020b), os meios de comunicação apresentam muitas falhas ao abordar temas climáticos. Muitos estudos têm se dedicado a examinar e analisar a cobertura da mídia sobre o assunto "mudanças climáticas" em diversos países, como, por exemplo, nos Estados Unidos (ANTILLA, 2005). No entanto, ainda existe uma lacuna no conhecimento, com poucos trabalhos no Brasil, quando se trata de outros fenômenos climáticos, como, por exemplo, a seca.

Esse interesse da comunidade científica visa contribuir para que as informações sejam divulgadas corretamente, a fim de que o público seja bem informado sobre qualquer assunto de cunho climático e meteorológico.

Em relação à seca, nas matérias divulgadas pelos jornais aparecem com frequência os conceitos (paradigmas) "combate à seca" e "convivência com a seca/semiárido". Nos dias atuais, esse debate

\begin{tabular}{llllll}
\hline Caminhos de Geografia & Uberlândia - MG & v. 22, n. 84 & dez/2021 & p. 136-153 & Página 138
\end{tabular}


tem se intensificado em diversas camadas da sociedade civil em virtude de sua importância. É uma discussão fundamental por promover reflexões sobre as ações e políticas públicas norteadas por esses paradigmas com objetivos absolutamente distintos.

\section{Histórico do combate à seca e da convivência com a seca e o semiárido}

Os estudos científicos sobre a seca iniciaram no século XIX, precisamente na segunda metade, em função da repercussão deste fenômeno no povoamento e nas atividades econômicas no sertão do Nordeste, marcando o período pela busca de explicação das causas físicas da seca nesta região (SILVA, 2007).

Desde o período republicano, as políticas públicas empregadas no semiárido brasileiro objetivaram corrigir distorções conjunturais, em decorrência do fenômeno das secas, porém, nenhuma delas alcançou resultados permanentes, com a intervenção, inclusive, do poder público no Nordeste, que sempre ocorreu por meio de ações centralizadoras e reducionistas, sendo concretizadas com a criação de órgãos nacionais direcionados ao combate à seca, "os quais se transformavam em objeto de disputas políticas entre os diversos segmentos da elite rural" (PASSADOR e PASSADOR, 2010, p. 70). Além do mais, as políticas públicas para essa região se restringiam às obras de infraestrutura hídrica, bem como ações emergenciais, assistencialistas e dispersas (ROCHA NETO, 1999).

De acordo com Passador e Passador (2010), existiram três períodos das políticas públicas relacionadas ao combate à seca. O primeiro período data do ano de 1877 até os anos 40 do século XX, no qual o Estado atuava por meio de "medidas de salvação, isto é, distribuindo alimentos entre os retirantes que chegavam às capitais, além de esmolas aos que permaneciam no interior". No segundo período (1950-1970), o interesse da política anti seca centrava-se no aproveitamento racional dos recursos hídricos e não mais nas obras de açudagem. Nesse período, o governo federal criou a Comissão do Vale do São Francisco (CVSF), em 1948, o Banco do Nordeste do Brasil em 1952 e a SUDENE, em 1959 (SANTOS, 1986). O terceiro período, iniciado a partir de 1970, foi definido pelo estabelecimento de vários programas, por exemplo, Proterra (1971), Provale (1972), Polonordeste (1974), Projeto Sertanejo (1976) e Prohidro (1979).

As ações desenvolvidas por tais organizações do Estado se pautavam na construção de estradas descontínuas, grandes açudes públicos, poços, principalmente a "construção de milhares de pequenos e médios açudes dentro de propriedades privadas", visando assegurar água para a produção agropecuária e o funcionamento de agroindústrias (PASSADOR e PASSADOR, 2010).

Em decorrência do agravamento da crise socioeconômica e política na região, na década de 1950, autoridades sociais do Nordeste começaram a pressionar o governo federal em prol do desenvolvimento dessa região (SILVA, 2007). Em 1958, o economista Celso Furtado elaborou um documento em nome do Grupo de Trabalho para o Desenvolvimento do Nordeste (GTDN) revelando que as intervenções do Governo durante os eventos de secas não alcançaram êxito no sentido de modificar as causas do problema (FURTADO, 1959).

No ano de 1959, com a criação da SUDENE, a Companhia do Vale do São Francisco focou em investimentos de projetos voltados para agricultura irrigada na sua área de atuação (IPEA, 1990). Com o surgimento da SUDENE, buscou-se uma acentuada mudança nas diretrizes das ações governamentais no Nordeste. Em decorrência do abandono das propostas de reformas substanciais na região, no contexto da ditadura militar, a concepção de "modernização econômica e tecnológica" ocupa posição de destaque como pilar do desenvolvimento dessa região (SILVA, 2007). Em 1970, o governo federal começou a priorizar o investimento de projetos mais abrangentes no fomento do desenvolvimento da agricultura irrigada no semiárido (IPEA, 1990), que, na perspectiva de Silva (2007), "a agricultura irrigada, com especialização na fruticultura para exportação, tornou-se a solução para os problemas da seca no sertão".

No entanto, segundo o Instituto de Pesquisa Econômica Aplicada - IPEA (1990), os investimentos para a expansão da área irrigada na região semiárida agravaram a sua rígida e desigual estrutura fundiária. A maioria da região semiárida apresentava uma economia tradicional e estática e a condição (estrutural) de pobreza "ainda se transformava em calamidades nas estiagens prolongadas", 
sem contar o agravamento dos problemas ambientais, tais como o processo de desertificação e a poluição de bacias hidrográficas (SILVA, 2007, p. 467).

Em 1956, o governo federal estabeleceu o Grupo de Trabalho para o Desenvolvimento do Nordeste (GTDN), cuja relevância teve como base a identificação das discrepâncias regionais. Conforme o GTDN, foram necessárias medidas amplas e maiores investimentos para o desenvolvimento da região. Essa fase foi nomeada desenvolvimento planejado, quando as políticas anti seca buscaram se fundamentar em análises mais cautelosas da realidade (PASSADOR e PASSADOR, 2010).

No governo de Juscelino Kubitschek (1959), na tentativa de solucionar os problemas das secas no Nordeste, criou-se o propósito da industrialização e a superação dos problemas agrícolas, além da colonização das terras despovoadas no Maranhão e no Oeste da Bahia, utilizando melhor as bacias hidrográficas e os açudes do Nordeste para irrigação (MALVEZZI, 2007).

Cita-se, também, a Companhia Hidroelétrica do São Francisco (CHESF), criada em 1945, com o objetivo pleno de aproveitar as águas do rio São Francisco, a partir da construção de quatorze hidrelétricas para geração de energia. A CHESF gerou transtornos em razão das construções de barragens que ocuparam muitos terrenos e por ter ocorrido a transferência de quatro cidades, sem mencionar os impactos promovidos ao meio ambiente (MALVEZZI, 2007).

Para Passador e Passador (2010), essas políticas públicas no semiárido nordestino, dentre outras, se demonstraram incompletas e fragmentadas, visto que, com a mudança de governo, os projetos do governo anterior eram interrompidos ou alterados. Além do mais, Silva (2003) enfatiza que independentemente da situação em que as famílias do semiárido encontravam-se, as intervenções do Estado se destinavam mais para atender os interesses políticos dos coronéis, nas perdas dos rebanhos e nas suas riquezas do que nas necessidades das famílias sertanejas. Sendo assim, as oligarquias se beneficiavam com a seca, fazendo deste fenômeno climático um grande negócio que foi denominado como "indústria da seca".

$\mathrm{Na}$ perspectiva do paradigma combate à seca, o semiárido é entendido segundo uma óptica utilitarista de ocupação e de aproveitamento de seus recursos, convertendo-os em riquezas. Os empreendimentos do Estado seguem esse fundamento. A seca surge como um obstáculo da natureza, algo que deve ser combatido. Por essa razão, a lógica da seca é simplista e implica na continuidade da miséria. "Funciona como uma estratégia perversa de manutenção e controle de uma região que, a princípio, e com exceções, não cabe na lógica do modelo de desenvolvimento que predomina" (SILVA, 2003). Na década de 1980, eclode outro discurso sobre a realidade regional e os meios sustentáveis para o desenvolvimento do semiárido brasileiro. Organizações não governamentais (ONGs) atuantes nessa região e instituições públicas de pesquisa e extensão desenvolveram propostas e praticaram alternativas fundamentadas no conceito de convivência com a seca e o semiárido, como exemplo a Empresa Brasileira de Pesquisa Agropecuária (EMBRAPA), que em 1982, lança um documento nomeado convivência do homem com a seca (SILVA, 2003).

Em 1999, diversos atores sociais, como organizações não governamentais, sindicatos rurais, cooperativas, associações religiosas, movimentos ambientais, entre outros, constituíram a Articulação Semiárido Brasileiro (ASA), no decorrer da realização do Fórum Paralelo da Sociedade Civil, ocorrido na capital pernambucana, Recife, que teve por princípio promover um espaço de discussão participativa entre os diversos atores sociais para a formulação de propostas que pudessem transformar a realidade local por meio de ações conjuntas, pautadas nos ideais de convivência com a região semiárida, a partir do protagonismo social das populações residentes, visando o desenvolvimento regional de forma sustentável frente aos problemas socioambientais presentes no território (DUTRA, 2017). A Articulação Semiárido Brasileiro centraliza suas ações de convivência com o SAB a partir do direito ao acesso à água e à terra. Durante esse fórum, a ASA divulgou um documento intitulado "Declaração do Semiárido" afirmando ser concebível a convivência com essa região e, em especial, com as secas. O documento apresenta um conjunto de propostas fundamentadas nos pressupostos da "conservação, uso sustentável e recomposição ambiental, e a quebra do monopólio de acesso à terra, à água e aos outros meios de produção" (SILVA, 2003).

Dentre as propostas estabelecidas na Declaração do Semiárido, destacam-se as seguintes: conviver com o fenômeno da seca; orientar investimentos pautados nos princípios da sustentabilidade ambiental; empoderar a sociedade civil; inclusão de mulheres e jovens nas tomadas de decisões;

$\begin{array}{lllll}\text { Caminhos de Geografia } & \text { Uberlândia - MG } & \text { v. 22, n. 84 } & \text { dez/2021 } & \text { p. 136-153 Página } 140\end{array}$


preservação e conservação dos recursos naturais e buscar financiamento para projetos de convivência (ASSIS, 2012; DUTRA, 2017).

Uma das primeiras medidas adotadas pela Articulação Semiárido Brasileiro para a convivência com o fenômeno da seca no semiárido foi a implantação do Programa Um Milhão de Cisternas, com o objetivo de captar a água da chuva (PONTES e MACHADO, 2012). Dentre as tecnologias que se destinam à captação e armazenamento da água de chuva, cita-se a cisterna de placas de cimento, que coleta a água caindo no telhado. A sua construção é relativamente acessível e econômica. Geralmente, é construída por pedreiros das comunidades com a cooperação das famílias beneficiadas. A água dessa cisterna é utilizada para consumo, e, de modo geral, favoreceu a melhoria da saúde da população, em particular das crianças contaminadas por doenças acarretadas pela poluição da água dos barreiros (DUQUE, 2008, p. 138). O semiárido é concebido enquanto um complexo de ecossistemas com os seus limites e as suas potencialidades. Trata-se de um espaço onde é possível construir ou resgatar relações de convivência entre os seres humanos e a natureza, com base no tripé da sustentabilidade ambiental, da qualidade de vida das famílias sertanejas e do incentivo às atividades econômicas apropriadas (SILVA, 2003).

Nesse sentido, baseado nos conceitos elaborados por Baptista e Campos (2013), a convivência com o semiárido é viver, produzir e desenvolver-se a partir de uma visão que não se centra na valorização e promoção da concentração de bens, mas que prioriza a partilha, a justiça e a equidade, buscando a preservação e conservação da natureza. Não significa, também, apenas fazer uso de tecnologias diferentes, quer sejam baratas ou caras. Significa ter como base uma proposta de desenvolvimento que considera a viabilidade do semiárido, a inteligência e capacidade do seu povo, que vê a natureza do semiárido rica e possível, desde que o homem se relacione com ela de modo adequado e que haja políticas públicas pertinentes (BAPTISTA e CAMPOS, 2013).

O conceito de "convivência com o semiárido", formulado em contraposição ao conceito de "luta contra as secas", mobilizou a sociedade civil e motivou na criação de referências tecnológicas e organizativas, projetadas para um novo padrão de políticas públicas (mais duradouras), estruturantes, que proporcionassem a convivência com o semiárido de modo que as ações de socorros pudessem ser absolutamente recusadas (DUQUE, 2008).

Silva (2003) destaca que a perspectiva desse paradigma "requer e implica um processo cultural, de educação, de uma nova aprendizagem sobre o meio ambiente, dos seus limites e potencialidades". Exige mudança na forma de pensamento, sentimento e ação de acordo com o seu meio de vida. Isto quer dizer que o conceito de convivência abrange a percepção da complexidade e exige uma abordagem integrada do semiárido brasileiro, tornando possível o entendimento das dimensões natural, social, econômica, política e cultural.

Esse paradigma viabiliza melhores condições de vida para a população que habita no semiárido, bem como a sua permanência nessa região, contribuindo ainda para fortalecer a identidade local, a preservação dos costumes e tradições e a intensificação do vínculo com a terra (SILVA, 2003; DUQUE, 2008). Portanto, o conceito de convivência com a seca não prega apenas a garantia do acesso à água para o consumo ou produção, mas, também, a formulação de ações voltadas para o desenvolvimento local, inclusão social e a promoção de autonomia aos sujeitos historicamente excluídos dos processos de decisão.

\section{Confronto entre o modelo combate à seca e o modelo convivência com o semiárido.}

Compreende-se, desse modo, que o combate à seca e a convivência com o semiárido são modelos criados para projetar o desenvolvimento do semiárido brasileiro, trabalhando em diferentes dimensões. O primeiro prega que a solução para essa região é "acabar" com a seca por meio de obras hídricas, carro-pipa, bolsa estiagem, frente de trabalho. No entanto, essas obras, em sua maioria, não beneficiavam a população mais vulnerável à seca, mas apadrinhavam os grandes donos das terras, coronéis e elite local, visto que as obras eram feitas dentro de suas propriedades, beneficiando os detentores do poder local e regional, em detrimento dos que mais necessitam da água (DUTRA, 2017; SANTOS, 2020). 
O segundo modelo atua no sentido de ensinar que é impossível lutar contra a seca, mas que é possível conviver com o clima semiárido, sendo viável o desenvolvimento sustentável, garantindo a segurança alimentar e a qualidade de vida da população. Essa nova percepção suprime "as culpas" designadas às condições ambientais, permitindo ter uma nova visão acerca do Semiárido baseada nas suas potencialidades e riquezas, características ao ambiente, proporcionando mudanças práticas na qualidade de vida da sociedade sertaneja (SANTOS, 2020).

Assim, o paradigma de convivência com o semiárido requer esforços nas diversas esferas da sociedade para que se possa viver de forma digna e humana frente aos problemas enfrentados pela população local.

Enquanto a lógica do primeiro centra-se unicamente na solução hídrica, a convivência com o semiárido defende a ideia de que é plenamente preciso o conhecimento holístico do semiárido, buscando, ao longo dessa perspectiva, adaptar-se diligentemente ao ambiente. Conclui-se, então, que o conceito de convivência é antagônico ao conceito de combate à seca, pois sua formulação é fundamentada na mobilização social para a criação de políticas públicas estruturais e eficazes para a convivência com o semiárido.

Tendo em vista a extrema relevância dessa discussão, faz-se necessário analisar como esses conceitos são apresentados pela mídia impressa. Esta é uma fonte de informação creditada pela massa, além de ser muito influente na construção de opiniões de um determinado assunto.

\section{METODOLOGIA}

Para analisar os conceitos de combate e convivência à seca, presentes nas matérias disseminadas pela mídia na Bahia, o presente estudo utilizou como procedimento metodológico a análise de conteúdo, que é um conjunto de técnicas de análise das comunicações, cuja finalidade consiste em obter, por procedimentos objetivos e sistemáticos de descrição do conteúdo das mensagens, indicadores (quantitativos ou não) que viabilizem a inferência de conhecimentos referentes às condições de produção/recepção destas mensagens, conforme descrito por Bardin (1977).

O "Correio da Bahia" (atual Correio) e o "A TARDE" foram escolhidos por constituírem os veículos de maior circulação no estado. As matérias dos jornais foram consultadas na Biblioteca Pública do Estado da Bahia. A análise recaiu sobre as matérias publicadas entre os anos de 2012 e 2015.

A análise qualitativa dos conceitos (convivência e combate à seca) se deu sob as seguintes abordagens ou métricas:

1. Definição: como o conceito dos termos foi construído e com que tipo de ideia foi relacionado;

2. Coerência: avaliar se os termos empregados têm coerência com a mensagem escrita;

3. Estrutura: como é a estrutura das notícias (descritiva, generalista ou opinativa);

4. Significado da Seca: como é feita a abordagem acerca do fenômeno climático a partir de termos técnicos encontrados nas notícias.

Para subsidiar a fase final de análise, inferências e interpretações, foram comparados os conteúdos construídos nas notícias com informações extraídas de bibliografia especializada na área.

\section{RESULTADOS E DISCUSSÃO}

Na figura 1 é possível observar que foi identificado um total de 249 matérias, em ambos os jornais, publicadas com a temática destacada "Seca no Semiárido Baiano". Desse total, a partir de uma revisão crítica e sistemática destas matérias, 48 notícias foram identificadas com texto relacionado aos dois paradigmas antagônicos de desenvolvimento: "Combate à Seca" e "Convivência com o Semiárido".

Verificou-se que, do total das 48 notícias, 33 utilizaram o termo "Combate à seca", o que equivale a $68,7 \%$, e uma porcentagem menor $(31,3 \%)$ foram veiculadas fazendo referência ao termo "Convivência com a seca". Portanto, constatou-se que a maioria das notícias estão fundamentadas no discurso do combate à seca.

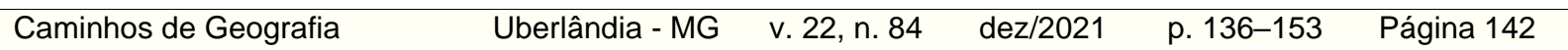




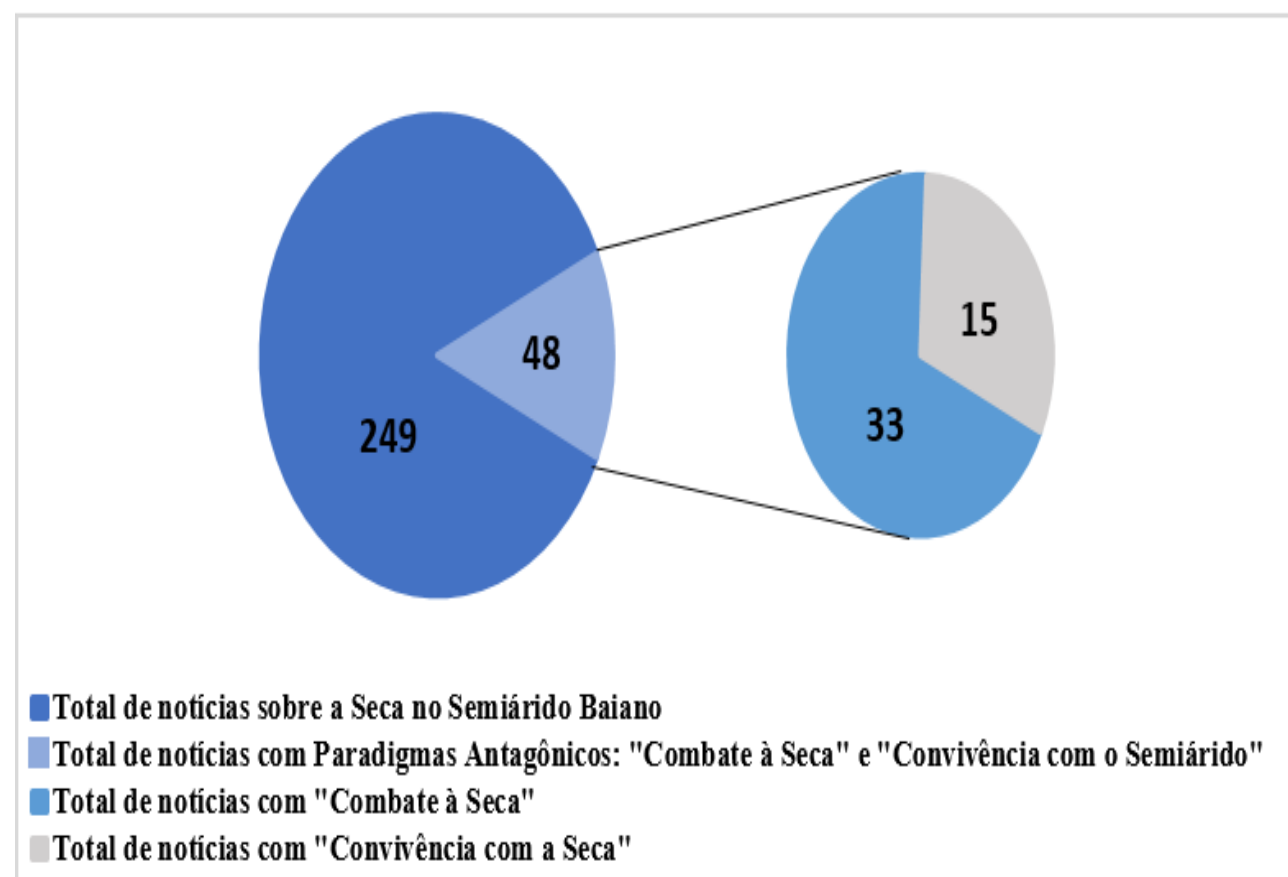

Fonte: os autores, a partir dos dados utilizados no presente estudo, 2020.

Majoritariamente, as notícias que abordam o combate à seca são descritivas e, em seu conteúdo, relatam as medidas paliativas executadas pelo governo federal, como construção de barragens, carros-pipas, bolsa estiagem, distribuição de cestas básicas, bem como a liberação de recursos federais. As notícias que possuem um caráter opinativo não provêm diretamente de jornalistas e sim de representantes da sociedade civil, membro de algum órgão público e, poucas vezes, de políticos. Adicionalmente, verificou-se que os textos personificam a seca, como pode ser constatado nas publicações dos dias 11 de março de 2012, 19 de maio de 2013 (A TARDE) e 04 de maio de 2012 (CORREIO), (Figura 2). 
Rafael Vinicius de São José

Priscila Pereira Coltri Roberto Greco

Kezia Andrade dos Santos Ivonice Sena de Souza

Cobertura jornalística o perigo climático (seca) 2012-2015 na Bahia: entre o combate e a convivência com a seca

Guilherme Almussa Leite Torres Ralph Charles

Figura 2- Matérias publicadas nos jornais analisados nos dias: a) 11 de março de 2012; b) 19 de maio de 2013 e c) 04 de maio de 2012.

11-03-12 (A TARDE)

CLIMA Estiagem atinge com força comunidades do norte, nordeste, centro-oeste e sudeste da Bahia Seca coloca 75 municípios em estado de emergência

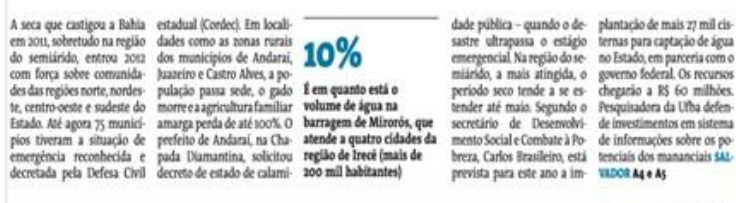

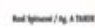

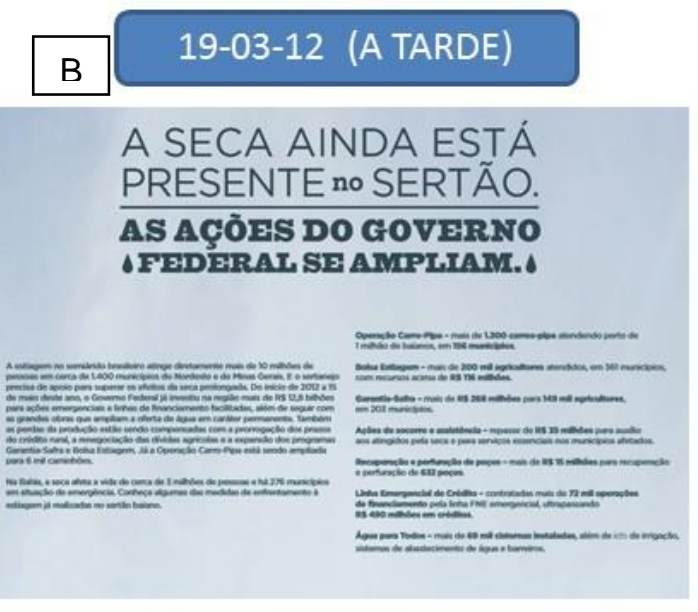

A SECA AINDA ESTÁ PRESENTE no SERTÃO AS ACÕES DO GOVERNO

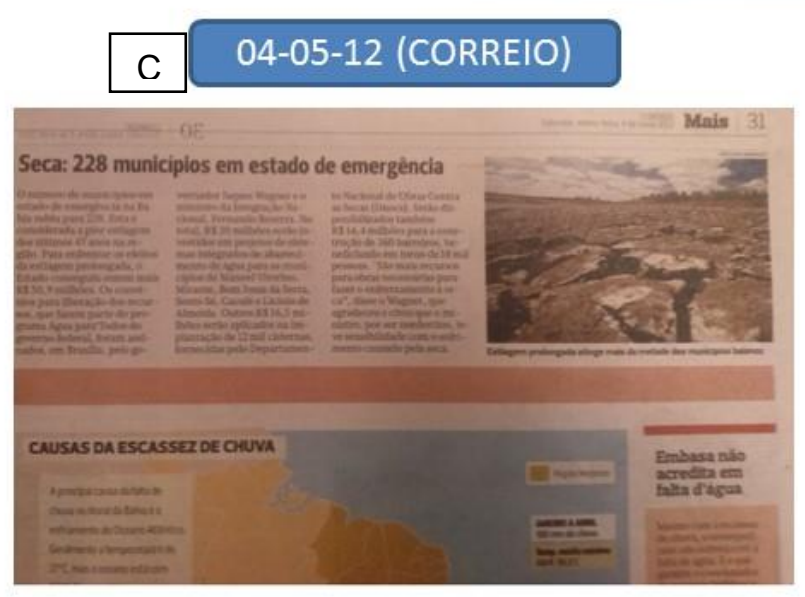

Fonte: Jornal "A tarde e Correio" (2012). 
$\mathrm{Na}$ figura 2, nas matérias publicadas em 11 e 19 de março de 2012, a seca é personificada, pois estas matérias, respectivamente, informam que a seca colocou 75 municípios em estado de emergência e que o evento climático permanece no sertão.

A matéria (divulgada em 11 de março de 2012) poderia relatar que, na verdade, os municípios decretaram estado de emergência, certamente, em virtude das suas vulnerabilidades sociais e não exclusivamente devido à severidade da seca.

O texto publicado em 19 de março de 2012 perdeu a oportunidade de informar sobre a complexidade que existe em determinar o início e o fim deste fenômeno climático. Mais interessante seria abordar que a seca é recorrente em regiões semiáridas, mas que os seus efeitos dependem também das condições socioeconômicas e educacionais da população afetada.

As notícias que apresentam personificação do perigo climático e propostas de medidas paliativas transmitem ao público a visão de que a seca não é um fenômeno recorrente no semiárido, ignorando as características climáticas locais. As duas matérias (figura 2) poderiam contribuir com a discussão relacionada à importância de uma gestão eficiente deste risco climático, no entanto, ambas reforçam as narrativas do combate à seca.

Boykoff (2007) argumenta que a cobertura da mídia ambiental tem uma importante atuação na percepção pública dos assuntos climáticos e, quando a mensagem transmitida é inverídica, influencia negativamente na maneira como os diferentes indivíduos ou sociedade percebem a região e o clima local.

Mendonça e Danni-Oliveira (2007, p. 11) escreveram que desvendar a dinâmica dos fenômenos naturais e o comportamento da atmosfera foi crucial para que os grupos sociais ultrapassassem a condição de simples indivíduos subordinados às intempéries naturais e alcançassem não apenas a compreensão do funcionamento de alguns fenômenos, mas também a "condição de utilizadores e de manipuladores" de tais fenômenos em várias escalas. Conti (2011) ressalta que compreender fenômenos como secas, enchentes e elevação de temperatura não deve ser apenas preocupação de cientistas, mas de todos os cidadãos, buscando conhecer as diversas dimensões destes fenômenos, sendo, portanto, capaz de exigir do Estado e da sociedade ação efetiva de preservação do meio ambiente e, por conseguinte, da vida.

Essa preocupação do homem com os fenômenos da atmosfera é muito antiga, visto que as civilizações já organizavam suas atividades em virtude do clima e do espaço geográfico, conforme relatado em DINIZ (2012). Como exemplo, a autora cita os egípcios, que se organizaram e se fixaram nas planícies do rio Nilo, estabelecendo seu império por séculos, em decorrência da disponibilidade de condições naturais favoráveis, e os povos babilônios, que ocuparam a região da Mesopotâmia (entre os rios Tigres e Eufrates), onde havia a presença abundante de água e clima ameno, condições altamente favoráveis ao desenvolvimento de atividades como agricultura, pecuária, dentre outras.

Um importante caminho para alcançar essa proposta, apresentada por Conti (2011) e Mendonça (2007), pode ser por meio da educação científica da população que habita em regiões de riscos climáticos e meteorológicos. No semiárido brasileiro, onde existe um alto risco de seca, a preparação científica dos cidadãos desta região, sem dúvida, ofereceria subsídios para a compreensão da dinâmica ambiental regional, bem como para a produção de tecnologias sustentáveis e eficientes de convivência com o semiárido.

O sertanejo cientificamente alfabetizado teria mais habilidade para refletir sobre as características físicas e sociais do semiárido, construir a sua própria percepção sobre esta região e superar os adjetivos pejorativos, historicamente, atribuídos ao semiárido e ao fenômeno das secas.

A alfabetização científica pode ser compreendida como "o conjunto de conhecimentos que facilitariam aos homens e mulheres fazer uma leitura do mundo onde vivem" (CHASSOT, 2000, p. 19), com vistas à sua transformação. Portanto, "seria desejável que os alfabetizados cientificamente não apenas tivessem facilitada a leitura do mundo em que vivem, mas entendessem as necessidades de transformá-lo - e, preferencialmente, transformá-lo em algo melhor" (CHASSOT, 2003, p.94).

\begin{tabular}{lllll}
\hline Caminhos de Geografia & Uberlândia - MG & v. 22, n. 84 & dez/2021 & p. 136-153 Página 145
\end{tabular}


O processo de alfabetização em ciência deve ocorrer de forma contínua, transcendendo o período escolar, o que exige a aquisição incessante de novos conhecimentos; "escolas, museus, programas de rádio e televisão, revistas, jornais impressos e a mídia em geral devem se colocar como parceiros nessa empreitada de socializar o conhecimento científico de forma crítica para a população (KRASILCHIK; MARANDINO, 2007, p. 17).

Tendo em vista o contexto apresentado acima, compete à escola e à sociedade promover condições de acesso e apropriação do conhecimento científico à população de maneira que assegure a efetiva participação nos processos de tomada de decisão (BYBEE, 1995; ROBERTS, 2007; KRASILCHIK e MARANDINO, 2007; SANTOS, 2007; CACHAPUZ et al., 2011). Neste sentido, ressaltamos que alfabetizar cientificamente o sertanejo constitui um aspecto de singular relevância, visto que este estará mais preparado para participar efetivamente do processo de construção de uma gestão integrada da sua própria realidade, ou seja, da sua região e dos riscos climáticos regionais (estiagens e secas).

Nas notícias analisadas, no geral, verifica-se que estas não contribuem para promover uma alfabetização científica do leitor, além disso, diferentes atores da região do semiárido (jornalistas, moradores, agricultores, representantes de órgãos governamentais, autoridades públicas e organizações da sociedade civil) apresentam o mesmo discurso a respeito da seca, enraizado no paradigma de combate à seca, e praticamente sem nenhuma base científica.

Verificou-se que a maioria das notícias foi descritiva, sendo ainda possível identificar que os investimentos do governo para essa região abrangem ações emergenciais, como exemplo cita-se a matéria divulgada dia 03 de abril de 2013, intitulada "SOCORRO: Verbas e medidas contra estiagem foram anunciadas pela presidente durante reunião da Sudene, em Fortaleza/ Nordeste terá $R \$ 9$ bilhões para enfrentar seca" (Figura 3).

Figura 3 - Matéria publicada no jornal “A Tarde” referente ao dia 03 de abril de 2013.

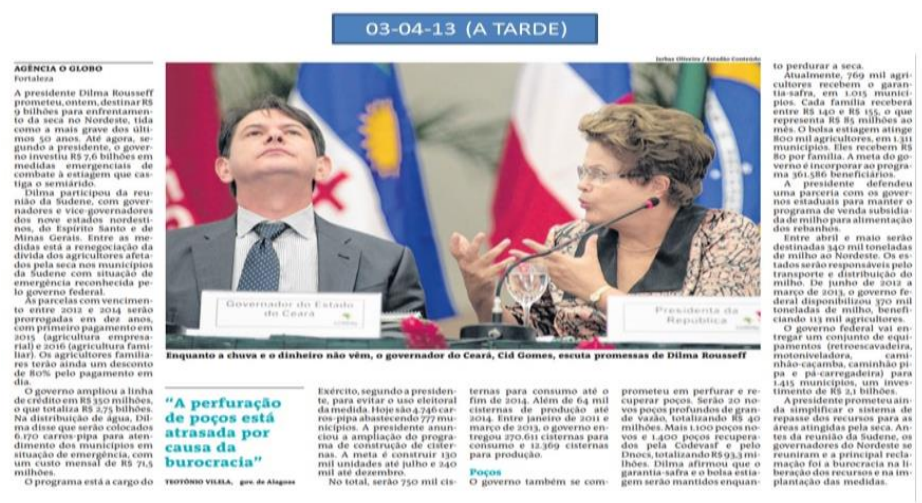

Fonte: Jornal "A tarde" (2013).

Pontes e Machado (2012) descrevem que a política do combate à seca favorece a estagnação da população em detrimento de novas possibilidades ao sertanejo, aquele que habita o sertão, com seu ambiente e suas peculiaridades. Casos opostos são descritos, por exemplo, na Califórnia, EUA, onde a estrutura econômica reduz a vulnerabilidade à seca. Segundo Sumner (2015), na década de 1920, a agricultura californiana era pautada no uso da água, mas a mudança dos métodos de consumo de água residual e o setor de serviço tornaram a economia menos dependente do suprimento abundante de água e menos afetada pela escassez hídrica. A longa história de seca na Califórnia levou ao acúmulo de infraestrutura, instituições e mudanças nas demandas de água adaptadas às secas (PISANI, 1984), o que não aconteceu ao longo da história das secas na região do Semiárido Brasileiro. Com base em Lund et al. (2018), a Califórnia vem investindo na construção de um gerenciamento dos efeitos de seca cada vez mais eficiente, e isso tem apresentado resultados positivos no que se refere à redução da vulnerabilidade à seca.

Assim como no Semiárido Brasileiro, ocorreu uma seca intensa no fragmento temporal de 2012 a 2016 na Califórnia. Para Lund et al. (2018), o manejo da água na Califórnia foi extraordinariamente

\begin{tabular}{lllll}
\hline Caminhos de Geografia & Uberlândia - MG & v. 22, n. 84 & dez/2021 & p. 136-153 Página 146
\end{tabular}


eficaz para essa seca, com exceção dos ecossistemas e do abastecimento de água potável rural. No entanto, com a ocorrência da seca ficou perceptível uma série de problemas, não identificados anteriormente. Esses novos problemas, segundo os autores, foram os gatilhos para inovações e resolução de problemas locais.

$\mathrm{Na}$ verdade, o Brasil não tem um gerenciamento eficiente do risco de seca, capaz de reduzir os desastres ambientais no SAB. Além disso, há um efeito do esquecimento. Por exemplo, enquanto na Califórnia, que é um estado que tem políticas desenvolvidas para conviver com a seca, os eventos atuais ou passados funcionam para mostrar o que precisa ser melhorado, no Brasil, por outro lado, depois que passa o período da seca há o esquecimento do evento, inclusive pela própria mídia.

No Brasil, na maior parte dos casos, a resposta dos representantes políticos é, via de regra, o combate à seca, abordando a seca como um limite ("imposto pelo clima") para o desenvolvimento dessa região. A seca é eleita como o mal dessa região, como constatado na matéria do dia 27 de março de 2012 pelo jornal "A Tarde" (Bahia terá R $\$ 10$ milhões para atuar no efeito da seca), como apresentado na Figura 4. Travassos, Souza e Silva (2003, p. 156) destacam que "ano após ano, governo a governo, atribuiu-se à seca como o elemento limitante do desenvolvimento da região nordestina".

Figura 4 - Matéria publicada no jornal "A Tarde" referente ao dia 27 de março de 2012.

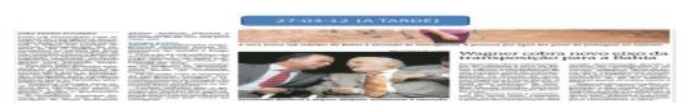

Fonte: Jornal "A tarde" (2012).

As ações paliativas, que são descritas pela mídia, no estado da Bahia, são insuficientes para resolver os problemas relacionados, sobretudo, à demanda de água da população, visto que, para Pontes e Machado (2012), por consequência, a cada ano a dependência dessas medidas se mantém ou aumenta, uma vez que são simplesmente paliativas. São ações que atenuam por curto tempo a falta de água, mas não melhoram as condições de vida da população, principalmente a rural.

Assim, corroborando com os autores Silva (2003) e Malvezzi (2007), há no semiárido brasileiro uma política de estagnação que impede a formulação de programas amplos de desenvolvimento projetado na ideia de convivência com o clima, para que a população vulnerável aprenda sobre o funcionamento deste fenômeno natural e seja capaz de se desenvolver nesse ambiente. Adicionalmente, há uma visão equivocada, na qual o clima tropical semiárido não foi, e nem é compreendido enquanto uma oportunidade para favorecer o avanço desta região.

Nesse aspecto, Ayoade (2010) ressalta que o clima é um elemento vital do ambiente tropical, que deve ser compreendido e considerado em qualquer programa de desenvolvimento que projete elevar o padrão e a qualidade de vida dessa população. Na região do semiárido baiano, no entanto, os grandes projetos para lidar com o regime climático estão, a todo o momento, enraizados no combate à seca.

Baseado no discurso de Santos (1986), observa-se que a pobreza dessa região é predominantemente de natureza política, ou seja, provém de uma deficiência da gestão pública, e não das condições climáticas. A influência das elites oligárquicas, o protecionismo ao grande agricultor e pecuarista, o pseudo-conformismo do sertanejo, a legislação que favorece a elite

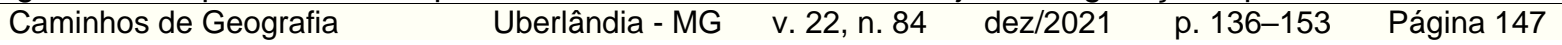


financeira são exemplos de motivos tradicionais que condicionaram e perfizeram a situação de pobreza (LUNA e BARBALHO, 1983).

Verificou-se que os jornais analisados confundem ambos os termos (convivência com o semiárido e combate à seca), porém, o combate à seca ganha destaque pelo fato de estar presente na maioria das matérias, veiculando informação incoerente e comprometendo o entendimento do público porque aborda uma visão pejorativa acerca da região e desconexa do ponto de vista climático.

Um exemplo de confusão conceitual entre os referidos termos é verificado na notícia publicada em 14 de abril de 2013 pelo "A Tarde", informando que: "Resultado de uma das maiores mobilizações da sociedade civil contra a seca, o Programa 1 Milhão de Cisternas (P1MC), lançado há dez anos, ainda não conseguiu atingir a meta, prevista para 2008 e que ajudaria a amenizar os impactos da maior estiagem dos últimos 50 anos".

Essa notícia informa que o trabalho da ASA, que atua no semiárido, a qual tem como incumbência "fortalecer a sociedade civil na construção de processos participativos para o desenvolvimento sustentável e a convivência com o Semiárido referenciados em valores culturais e de justiça social" (ASA, 2018, on-line), está pautado no combate à seca, o que não constitui uma verdade. A ASA é uma instituição que se posiciona politicamente contra o modelo de desenvolvimento alicerçado no combate à seca, e faz apologia, difusão e desenvolve - por meio de políticas públicas - o projeto político da convivência com o semiárido (ASA, 2018), como, por exemplo, o programa mencionado na notícia (P1MC). O P1MC (Programa de Formação e Mobilização para a Convivência com o Semiárido: um milhão de Cisternas Rurais) teve início em 1999. É um amplo programa de mobilização social que visa revelar como é possível os seres humanos viverem de forma digna e sustentável no semiárido (PONTES e MACHADO, 2012, p. 17).

Nota-se, portanto, na notícia veiculada em 13 de abril de 2013, a predominância da visão de um ambiente hostil e a característica negativa atribuída à seca. Esse discurso não é novo, mas tem sido recorrente, sobretudo, nos veículos de comunicação.

Aranha (2006) explica que esse discurso de combate à seca surgiu no fim do século XIX, em decorrência da grave crise enfrentada pela tradicional economia exportadora nordestina. Nesse contexto, as elites políticas e econômicas regionais recorreram ao uso de imagens reduzidas a cenários de seca como um argumento irresistível para extrair recursos junto ao governo federal, tendo como suposta finalidade "socorrer" a população "flagelada". Sendo assim, o autor ainda argumenta que a necessidade de modernizar a região por meio da construção de grandes obras públicas, que movimentassem altas somas de recursos públicos, era uma ideia defendida por esses representantes das oligarquias.

Para tanto, foram propagadas imagens distorcidas do semiárido brasileiro, relacionando-o a um ambiente de hostilidade e adversidade, além de inóspito (ARANHA, 2006). Assim, as notícias até hoje veiculadas têm apresentado o conteúdo de "clima hostil" e de "seca malévola", o que apenas contribui para o fortalecimento e a manutenção da indústria da seca.

Com base em conhecimentos da Climatologia, o conceito de combate à seca é extremamente inadequado e incorreto, uma vez que o "clima é um sistema complexo, regulado por múltiplas interações entre atmosfera, o oceano, a hidrosfera, a criosfera e a biosfera" (TEODORO e AMORIM, 2008). Estes autores afirmam que desde a formação da atmosfera terrestre, esse sistema tem sofrido alterações em diferentes eras geológicas, pelo fato de estar em contínua e frequente transformação. Desse modo, é inconcebível sustentar um paradigma que prega combater um fenômeno de ordem natural, uma vez que o homem não tem o controle do sistema climático.

Por outro lado, nas matérias analisadas, observa-se que a exposição do tema convivência com a seca e o semiárido acontece de forma tímida e equivocada, atrelando-o, muitas vezes, à construção de barragens hídricas. Sendo assim, a solução hídrica como resposta crucial (se não, única) para as problemáticas do semiárido brasileiro não está presente apenas no discurso de combate à seca, porém, na mídia, ela também é comumente ressaltada como a principal referência à convivência com a seca.

Convivência com o semiárido não é sinônimo de construção de poços e barragens, não se limita simplesmente à solução hídrica. A convivência com o semiárido passa por um processo de formação

\begin{tabular}{lllll}
\hline Caminhos de Geografia & Uberlândia - MG & v. 22, n. 84 & dez/2021 & p. 136-153 Página 148
\end{tabular}


das pessoas sobre o ambiente (social e físico) do semiárido, bem como funciona o clima e as suas variações, para que o clima tropical semiárido não seja visto como um fator negativo, mas, sim, como uma oportunidade (na medida que as atividades econômicas estejam estritamente associadas com o regime climático). A partir daí busca-se as estratégias de adaptação ao ambiente, viabilizando a vida nele (MACIEL e PONTES, 2015).

Raramente, as notícias abordam convivência com o semiárido (tipologia climática), sendo muito predominante nos discursos a expressão "convivência com a seca". Embora esteja se referindo ao conceito de convivência, esse fenômeno (seca) ainda aparece como o grande vilão das problemáticas do Nordeste brasileiro.

Ressalta-se, ainda, a inexistência de matérias que de fato relatam sobre a importância e necessidade da população do semiárido aprender sobre as características ambientais (clima, solo, relevo, vegetação, hidrografia, entre outros) dessa região, algo extremamente imprescindível para subsidiar a convivência com um determinado ambiente. Em decorrência disso, é fundamental a busca de mais conhecimento sobre o tema, bem como a sua popularização, para romper a visão reducionista acerca do semiárido e entender que existe diferença entre os paradigmas discutidos nesse estudo.

\section{CONSIDERAÇÕES FINAIS}

A análise acerca das matérias dos jornais envolvendo os termos convivência e combate à seca demonstrou que a maioria das notícias faz alusão ao conceito de combate à seca. Existem matérias que apresentam os termos como conceitos sinônimos. Essa forte apologia ao paradigma combate à seca não constitui um aspecto positivo, uma vez que o discurso do combate à seca é um equívoco climatológico.

As notícias que abordam o conceito "convivência com a seca", normalmente, estão atreladas à questão hídrica, construção de barragens e poços. Percebe-se que esse conceito ainda não foi compreendido no seu sentido amplo, sendo, portanto, apresentado a partir de uma visão generalizada.

No geral, grande parte das notícias analisadas associa a pobreza local e a falta de infraestrutura à seca, mas não divulgam que o problema não é o clima ou a irregularidade das chuvas, mas sim a forma como se deu a organização desse espaço em termos históricos, sociais, culturais e políticos. Grande parte das dificuldades impostas pelas estiagens nessa região decorrem, principalmente, do modelo econômico adotado para o desenvolvimento regional, conforme relatado no referencial teórico do presente estudo.

\section{AGRADECIMENTOS}

O presente trabalho foi realizado com o apoio da Coordenação de Aperfeiçoamento de Pessoal de Nível Superior (CAPES) - Código de Financiamento 001.

\section{REFERÊNCIAS}

A TARDE. A seca ainda está presente no sertão. Edição de 19 de março de 2012.

A TARDE. Seca coloca 75 municípios em estado de emergência. Edição de 11 de março de 2012.

A TARDE. INTEGRAÇÃO/ Convênio com ministério garante recursos emergenciais ao Estado/ Bahia terá $R \$ 10$ milhões para atuar no efeito da seca. Edição de 27 de março de 2012.

A TARDE. SOCORRO: Verbas e medidas contra estiagem foram anunciadas pela presidente durante reunião da Sudene, em Fortaleza Nordeste terá $\mathrm{R} \$ 9$ bi para enfrentar seca. Edição de 03 de abril de 2013.

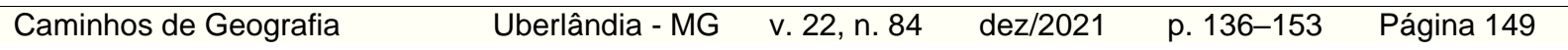


Cobertura jornalística o perigo climático (seca) 2012-2015 na Bahia: entre o combate e a convivência com a seca
Rafael Vinicius de São José Priscila Pereira Coltri Roberto Greco

Kezia Andrade dos Santos Ivonice Sena de Souza Guilherme Almussa Leite Torres Ralph Charles

ANTILLA, L. Climate of skepticism: US newspaper coverage of the science of climate change. Global Envronmental Change, v. 15, 2005.

ARANHA, G. B. Trem, modernidade e imaginário na Paraíba e região: tramas político-econômicas e práticas culturais (1880-1925). Campina Grande, PB: EDUFCG, 2006.

ASA. Articulação Semiárida Brasileira. Disponível em: <http://www.asabrasil.org.br/sobrenos/historia>. Acesso em: 16 set. 2018.

ASSIS, T.R.P. Sociedade civil e a construção de políticas públicas na região semiárida brasileira: 0 caso do Programa Um Milhão de Cisternas Rurais (P1MC). Revista de Políticas Públicas, v. 16, n. 1, p. 179-190, 2012. Disponível em <http://www.periodicoseletronicos.ufma.br/index.php/rppublica/article/view/1189>. Acesso em $28 \mathrm{de}$ dez de 2020.

AYOADE, J. O. Introdução à Climatologia para os Trópicos. 13ª ed. - Rio de Janeiro: Bertrand Brasil, 2010.

BAPTISTA, N. de Q.; CAMPOS, C. H. Caracterização do Semiárido Brasileiro, 2013. In: CONTI, I. L.; SCHOEDER, E. O. Convivência com o Semiárido Brasileiro: Autonomia e Protagonismo Social. Editora IABS, Brasília-DF, Brasil, 2013. In: BAPTISTA, N. de Q.; CAMPOS, C. H. Caracterização do Semiárido Brasileiro, 2013. p. 55 - 62.

BARDIN, L. Análise de conteúdo. Lisboa: Edições 70 Ltda, 1977.

BYBEE, Rodger W. Achieving scientific literacy. The Science Teacher, Arlington, v. 62, n. 7, p. 28-33, 1995.

BOYKOFF. M. T. From convergence to contention: United States mass media representations of anthropogenic climate change science. Transactions of the Institute for British Geography,32 (4)(2007), pp.477-489.

BURITI, C. O.; BARBOSA, H. A. Um século de secas: por que as políticas hídricas não transformaram o Semiárido brasileiro? 1 ed. São Paulo: Chiado Books, 2018. p. 434.

CACHAPUZ et al. A necessária renovação do ensino das ciências. São Paulo: Cortez, 2011.

CHASSOT, A. Alfabetização científica: questões e desafios para a educação. ljuí: Editora Unijuí, 2000.

CHASSOT, A. Alfabetização científica: uma possibilidade para a inclusão social. Rev. Bras. Educ. n.22, Rio de Janeiro, 2003

CONTI, J. B. Clima e meio ambiente. São Paulo: Atual, 7. Ed. 2011. p. 96.

CORREIO. Seca: 228 municípios em estado de emergência. Edição de 04 de maio de 2012.

DINIZ, A. F. Estudo da variabilidade da pluviosidade (1994-2010) no município de Feira de Santana (Bahia) e seus reflexos na agricultura de sequeiros: o caso do milho. 2012. Dissertação (Programa de Pós-Graduação em Geografia) - Instituto de Geociências - Universidade Federal da Bahia. Salvador, 2012.

DUQUE, G. "Conviver com a seca": contribuição da Articulação do Semi-Árido/ASA para o desenvolvimento. In: Revista Desenvolvimento e meio ambiente, Curitiba, n.17, p.133-140, jan./jun., 2008. Curitiba: Editora UFPR, 2008. 
Cobertura jornalística o perigo climático (seca) 2012-2015 na Bahia: entre o combate e a convivência com a seca
Rafael Vinicius de São José Priscila Pereira Coltri Roberto Greco

Kezia Andrade dos Santos Ivonice Sena de Souza Guilherme Almussa Leite Torres Ralph Charles

DUTRA, C. K. T. O papel da articulação semiárido brasileiro (ASA) e o Programa Um Milhão de Cisternas (P1MC) no semiárido potiguar. 2017. 131f. Dissertação (Mestrado em Desenvolvimento e Meio Ambiente) - Centro de Biociências, Universidade Federal do Rio Grande do Norte, Natal, 2017.

FURTADO, C. A operação Nordeste. Rio de Janeiro: Instituto Superior de Estudos Brasileiros, 1959. p. 80 .

GOMES, U. A. F.; PENA, J. L. Confrontando a vulnerabilidade e indefensabilidade social: a experiência da Articulação no Semiárido Brasileiro (ASA). GEOUSP - Espaço e Tempo, São Paulo, p. $45-56,2012$.

HENNESSY, M.; HAWKINS, L.; JAMIESON, K.H. The 2014 Walrus Haul Out: A case Study of Selective Exposure to Environmental News Coverage. Journal Environmental Communication, v. $11,2017$.

IPEA. Instituto de Pesquisa Econômica Aplicada. Texto para discussão/ Instituto de Pesquisa Econômica Aplicada. - Brasília: Rio de Janeiro, 1990.

KRASILCHIK, M; MARANDINO, M. Ensino de ciências e cidadania. São Paulo: Moderna, 2007.

LUNA, L; BARBALHO, N. Coronel dono do mundo. Rio de Janeiro: Editora Cátedra/Pró Memória, 1983.

LUND, J, AZUARA, J. M, DURAND, J, STON, K. Lessons from California's 2012-2016 Drought. Journal of Water Resources Planning and Management, 2018. Disponível em: <https://ascelibrary.org/doi/full/10.1061/(ASCE)WR.1943-5452.0000984> Acesso em: 07 dez. 2018.

MACIEL, C.; PONTES, E. T. Seca e convivência com o Semiárido: adaptação ao meio e patrimonialização da caatinga no Nordeste brasileiro. 1. Ed. Rio de Janeiro: Consequência editora, 2015.

MALVEZZI, R. Semi-Árido: uma visão holística. Brasília: Confea, 2007.

MARANDINO et al. Educação em museus: a mediação em foco. São Paulo: Geenf/Feusp, 2008.

MARENGO, J. A.; CUNHA, A. P.; ALVES, L. M. A seca de 2012-15 no semiárido do Nordeste do Brasil no contexto histórico. Revista Climanálise, v. 4, n. 1, p. 49-54. 2016.

MENDONÇA, F.; DANNI-OLIVEIRA, I. M. Climatologia: noções básicas e climas do Brasil. São Paulo: Oficina de Textos, 2007. p. 206.

NOBRE, L. F. D. P. Mídia Impressa e Meio Ambiente: Um estudo da Cobertura da mortandade de peixes no estuário do rio Pontegi. 2011. p. 114. Dissertação (Mestrado em Meio Ambiente e Desenvolvimento) - Centro de Biociências, Universidade Federal de Natal, Rio Grande do Norte, 2011.

NUNES, L. H. Riscos do clima ou riscos da comunicação? A cobertura jornalística do furacão Sandy (2012) em um periódico nacional. Revista Brasileira de Climatologia, v. 19, p. 54-73, 2016.

NUNES, L. H. O papel da mídia na difusão da informação climática: o El Niño de 1997-98. Geografia, v.32, n.1, 2007. P.29-50.

O'DONNELL, C.; RICE, E.R. Coverage of environmental events in US and UK newspapers: frequency, hazard, specificity, and placement. International Journal of Environmental Studies, vol. 65, n. 5, 2008 pp. 637-654.

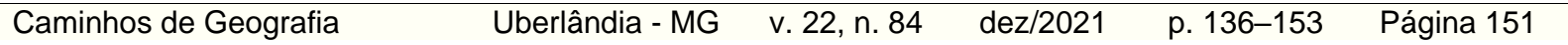


Cobertura jornalística o perigo climático (seca) 2012-2015 na Bahia: entre o combate e a convivência com a seca
Rafael Vinicius de São José Priscila Pereira Coltri Roberto Greco

Kezia Andrade dos Santos Ivonice Sena de Souza Guilherme Almussa Leite Torres Ralph Charles

PASSADOR, C. S.; PASSADOR, J. L. Apontamentos sobre as políticas de combate à seca no Brasil: Cisternas e Cidadania. Cadernos Gestão Pública e Cidadania, São Paulo, v. 15, n. 56, 2010.

PÉREZ-MARIN, A. M. et. al. Agroecological and Social Transformations for Coexistence With SemiAridity in Brazil. Sustainability, 9 (6), 2017.

PISANI, D. From the family farm to agribusiness: The irrigation crusade in California, 1850-1931. Berkeley, CA: University of California Press, 1984.

PONTES, E. T. M.; MACHADO, T. A. Desenvolvimento Sustentável e Convivência com o SemiÁrido: o caso do programa um milhão de cisternas rurais no nordeste brasileiro. Universidade Federal de Pernambuco, 2012. Disponível em: < www.agrisustentavel.com> doc > p1mc>. 24 p. Acesso em: 10 mai. 2018.

ROBERTS, D. A. Scientific literacy/Science literacy. In: ABELL, Sandra K.; LEDERMAN, Norman G. Handbook of research in science teaching and learning. New York: McMillan, 2007. p. 729-780.

ROCHA NETO, I. Sistemas Locais de Inovação dos Estados do Nordeste do Brasil. In: CASSIOLATO, J.E.; LASTRES, H.M. (Orgs). Globalização e Inovação Localizada: Experiências de Sistemas Locais no Âmbito do Mercosul. Brasília: IBICT/MCT. p.464-506. 25, 1999.

SAFIEL, U.; ADEEL, Z. Dryland systems. In: Hassan R, Scholes R, Ash N (eds) Ecosystems and human well-being, current state and trends, vol 1. Island Press, Washington, p. 625-658, 2005.

SANTOS, R. R. dos; NUNES, G, S. Nordeste: o desenvolvimento do homem rural. São Paulo: Nobel, 1986.

SANTOS, K. A. dos. Programa Cisternas nas Escolas e a sua contribuição para a convivência com a seca no Semiárido brasileiro. 2020. Dissertação de Mestrado (Programa de Pós-Graduação em Ensino e História de Ciências da Terra) Universidade Estadual de Campinas, Instituto de Geociências, Campinas, SP, 2020.

SANTOS, W. L. P. Educação científica na perspectiva de letramento com prática social: funções, princípios e desafios. Revista Brasileira de Educação, Rio de Janeiro, v. 12, n. 36, p. 474-550, set./dez. 2007.

SÃO JOSÉ, R. V. et al. Avaliação de vulnerabilidade agrícola à seca: um estudo de caso no semiárido do estado da Bahia. Caminhos de Geografia, v. 21 n. 77, p. 96-110, 2020a.

SÃO JOSÉ, R. V. et al. Seca no Semiárido Baiano e o Hidrometeoro (Chuva) no Contexto da Mídia Impressa do Estado da Bahia. Revista Brasileira de Geografia Física, [S.I.], v. 13, n. 1, p. 249-255, $2020 b$.

SÃO JOSÉ, R. V. de. A difusão da informação da natureza climatológica na época da seca no Semiárido baiano. 2019. Dissertação de Mestrado (Programa de Pós-Graduação em Ensino e História de Ciências da Terra) Universidade Estadual de Campinas, Instituto de Geociências, Campinas, SP, 2019.

SILVA, R. M. A. da. Entre o Combate à Seca e a Convivência com o Semi-Árido: políticas públicas e transição paradigmática. Revista Econômica do Nordeste, Fortaleza, v. 38, n. 3, 2007.

SILVA, R. M. A. da. Entre dois Paradigmas: Combate à seca e convivência com o Semi-Árido.

Sociedade e Estado, Brasília, v. 18, n. 1/2, p. 361-385, 2003. 
STEINKE, E.T.; SAITO, C.H.; ANDRADE, G. de S.; GASPAR, L. Como a mídia impressa do Distrito Federal divulga fatos relacionados ao clima e ao tempo na época da estiagem. Geografia, v.31, n.2. 2006. p.347-357.

SUDENE. Superintendência de Desenvolvimento do Nordeste. Delimitação do semiárido.

Disponível em: < http://www.sudene.gov.br/delimitacao-do-semiarido> . Acesso em: 16 jun 2019.

SUMNER, D, A. California's severe drought has only marginal impacts on food prices. Agricultural and Resource Economics. Update 18 (5): 12-15, 2015.

TEODORO, P. H. M.; AMORIM, M. C. C. T. Mudanças climáticas: algumas reflexões. Revista brasileira de climatologia, v. 3/4, p. 25-36, 2008.

THAKER, J. ZHAO, X., LEISEROWITZ, A. Media Use and Public Perceptions of Global Warming in India. Environmental Communication, v. 11, 2017.

TORRES, F. T. P.; MACHADO, P. J. de O. Introdução à Climatologia. São Paulo: Cengage Learning, 2016.

TRAVASSOS, I. S.; de SOUZA, B. I.; da SILVA, A. B. Secas, desertificação e políticas públicas no semiárido nordestino brasileiro. Revista OKARA: Geografia em debate, v.7, n.1, p. 147-164, 2013.

UNITED NATIONS. Environment Management Group. Global drylands: a UN system-wide response. Geneve, SW: 2011. 132p.

UNITED NATIONS. Environment Management Group. Global drylands: a UN system-wide response. Geneve, SW: 2011. 132p.

Recebido em: 18/08/2020

Aceito para publicação em: 29/01/2021 